\title{
Social responsibility in the global village: What role for public and school libraries?
}

\author{
James Henri, Associate Professor, \\ Faculty of Education, University of Hong Kong \\ Sandra Lee, Sessional Lecturer, \\ Faculty of Education, University of British Columbia, Canada
}

\begin{abstract}
In our global village dominated by economic rationalism does the public library have a social conscience? Issues given prominence by Patricia Glass Schuman's Social Responsibilities and Libraries, published in 1976 were revisited. As an area of larger community structure and debates of public good, the perennial topic of interest is fast becoming the current hot topic of librarianship. Literacy and learning have long been critical areas where librarians focus service, skills and programming in public libraries. This research project seeks to examine how librarians perceive other issues that often go hand-in-hand with literacy to help individuals and society achieve full potential. The research in this presentation and paper is part of a coauthored book that primarily examined politics and the public library discussing issues given new flavour in a post 9/11 world, economic rationalism and social responsibility, public Library as Social Space, engaging the poor and those marginalized because of access limitations. Freedom of information and privacy are perennial issues for libraries. It is clear that literacy continues to be a key issue for public libraries. Researchers analyzed responses received from open-ended questions on library professional listservs and present findings that indicate what librarians perceive as the role of public libraries to further socially responsible policy. They provide some insight into the most compelling issues for librarians, and what changes in librarian's/library roles have been perceived since 9/11. The findings from the study are also presented in the context of the impact it bears for school libraries, outlining further studies in that area.
\end{abstract}

\section{Introduction}

Publicly funded libraries have a very important role as contributors to cultural cohesion and social growth. Libraries that serve the public play many roles as social agents for all age groups across society. Recently there has been a focus on the responsibility of these agencies to foster and even to deliver literacy and information literacy programs for children, young people, and the public generally (Brown, 2003; Skov, 2004). Indeed libraries have always articulated service in support of the public good as a core responsibility and have achieved this by promoting social inclusion and developing policies to encourage the integration of heterogeneous ethnic communities, helping those disadvantaged and challenged and facing an information divide.

The literature discussing libraries and social responsibility, published several decades ago requires a revisit in the context of contemporary politics. As well, poor communities and 
the needs of homeless people continue to be a public library concern and prominent issue of advocacy (Berman, 2000). It is time to revisit this debate as a central and defining role for information professionals as societies seek to advance an information literate citizenry as spelled out in the Alexandria Proclamation on Information Literacy and Lifelong Learning (Beacons of the information society, 2005).

\section{Information literacy}

- comprises the competencies to recognize information needs and to locate, evaluate, apply and create information within cultural and social contexts;

- is crucial to the competitive advantage of individuals, enterprises (especially small and medium enterprises), regions and nations;

- provides the key to effective access, use and creation of content to support economic development, education, health and human services, and all other aspects of contemporary societies, and thereby provides the vital foundation for fulfilling the goals of the Millennium Declaration and the World Summit on the Information Society; and

- extends beyond current technologies to encompass learning, critical thinking and interpretative skills across professional boundaries and empowers individuals and communities.

A strong argument can be mounted in support of the view that in a post 9/11 world social structure and information policy have changed and that this will have a major impact upon societies, (especially those societies that have championed intellectual freedom and free access to information for all), and the library of tomorrow. Core values in librarianship including literacy development must be reexamined in the context of new positions on social responsibility.

We put the case that cultural and political differences aside, the majority of information professionals who work in libraries that serve the general public, set their political compass in a libertarian quadrant. (http://www.politicalcompass.org/) Many would argue that libraries, especially publicly funded libraries within a democratic culture, have unique and compelling obligations to ensure equal access for all members of the communities they serve. If librarians who intend to serve the public were required to take a professional oath at graduation, or on employment, it would likely emphasize free and equal access to information.

Equal access has long been the clarion call of librarians, activists and non-activists alike. Library associations, together with advocacy groups aligned with libraries, have a long history of concentrated their activities around this issue as can be demonstrated by a raft of Intellectual Freedom Statements and Policies championed by the ALA (ALA, 2005).

The following extract from The Freedom to Read Statement is typically unambiguous. 
Now as always in our history, reading is among our greatest freedoms. The freedom to read and write is almost the only means for making generally available ideas or manners of expression that can initially command only a small audience. The written word is the natural medium for the new idea and the untried voice from which come the original contributions to social growth. It is essential to the extended discussion that serious thought requires, and to the accumulation of knowledge and ideas into organized collections.

We believe that free communication is essential to the preservation of a free society and a creative culture. We believe that these pressures toward conformity present the danger of limiting the range and variety of inquiry and expression on which our democracy and our culture depend. We believe that every American community must jealously guard the freedom to publish and to circulate, in order to preserve its own freedom to read. We believe that publishers and librarians have a profound responsibility to give validity to that freedom to read by making it possible for the readers to choose freely from a variety of offerings.

The freedom to read is guaranteed by the Constitution. Those with faith in free people will stand firm on these constitutional guarantees of essential rights and will exercise the responsibilities that accompany these rights.

We therefore affirm these propositions:

1. It is in the public interest for publishers and librarians to make available the widest diversity of views and expressions, including those that are unorthodox, unpopular, or considered dangerous by the majority.

Creative thought is by definition new, and what is new is different. The bearer of every new thought is a rebel until that idea is refined and tested.

Totalitarian systems attempt to maintain themselves in power by the ruthless suppression of any concept that challenges the established orthodoxy. The power of a democratic system to adapt to change is vastly strengthened by the freedom of its citizens to choose widely from among conflicting opinions offered freely to them. To stifle every nonconformist idea at birth would mark the end of the democratic process. Furthermore, only through the constant activity of weighing and selecting can the democratic mind attain the strength demanded by times like these. We need to know not only what we believe but why we believe it.

Similar statements developed for the UK are available (CILIP, 2005).See online www.cilip.org.uk/professionalguidance/foi/intellfreedom.htm

Policies that focus on children's rights have not been ignored. Typical statements have be adopted by Australian and Canadian professional associations (ASLA, 1994; ASLA, 2000, ATLC, 1995). Online at: Australia http://www.asla.org.au/policy/p_eilit.htm and http://www.asla.org.au/policy/p_bor.htm and 
Canada http://www.caslibraries.ca/files/StudentsBillEnglish.pdf

The extract from the ATLC document (ATLC, 1995) below is demonstrative of the power of the Canadian position on access to information.

We believe that all students should have the right to:

- access a wide range of print, nonprint and electronic learning resources at an appropriate level;

- explore materials expressing a variety of opinions and perspectives; and

- freely choose reading, viewing and listening materials for recreational and study purposes.

Meanwhile, librarians, wearing their various stripes continue their professional duties, and the world changes. Society, the economy and political values evolve or devolve into very different organisms. Anyone mature prior to 1994 would notice extreme differences after the rise of the Internet for public consumption and the proliferation of information-the new reality.

An entire discipline surrounds social psychology and one would expect recent research among those scholars to indicate very marked differences between society now and society a decade ago. Indeed, anyone over the age of 30 would be able to make this observation without empirical evidence.

In western countries, it is arguable that contemporary social milieu reflects changes that seem to have accelerated with the events following 9/11. There are concerns about the availability of information that informs the situation in Iraq and a post-9/11 response by governments that have impact on civil liberties in their attempts to prosecute people labeled as 'terrorists'. The authors also posit that in similar vein to the social upheaval in the US during the 'anti-communist' McCarthy era (McCarthyism, n.d.) that the events of 9/11 have resulted in stereotyping of groups and individuals and affected the way that that they are served by public organizations.

It is clear from the literature together with the reactions from a variety of professional organizations that the response of western governments in the post 9/11 era that has spawned the Patriot Act (SRRT, 2005) and the Multilateral Agreement on Investment (BCLA, 1998) has had a strong, and we would argue a negative, impact on the exclusivity and effectiveness of national information policy. Indeed, some would argue that these laws have placed the state and the profession of librarianship at odds with each other. 


\section{Purpose of the study}

If there have been changes in our political environment that threatened civil liberties and equal access to information in libraries, how are librarians that serve the general public responding, given their resolute and ethical stance on intellectual freedom?

Do public librarians concern themselves with the basic, ethical commitment to information? What do they perceive to be the social responsibility of libraries? Do they perceive a shift after 9/11 in the political challenges of: equal access, intellectual freedom, privacy, helping marginalized groups?

A greater understanding of the perceptions of librarians is hoped to provide a starting point for further studies of what issues are most compelling for information professionals and if there has been any shift in recent years. If not, it might be argued that marginalized groups and issues of equal access have not been significantly resolved or mitigated by our efforts and mission. This may lead to realization of even bigger problems in investigating why progress has been slow.

This exploratory study was the initial step in a larger multi-country study and provided the opportunity to identify key issues that will underpin that study. The study also sought to inform a related study in the social responsibility of school libraries, investigating common ground and exploring special differences for information professionals serving school communities.

\section{Research questions}

- $\quad$ Have library and librarian's roles changed since 9/11? And if so how?

- What do librarians perceive as the role of libraries serving the general public to further socially responsible policy and

- What issues of social responsibility are most compelling for librarians?

- What is the impact for school libraries and what further studies are needed in that area?

\section{Methodology}

A critical review of the literature was employed as a means to identify positions held on the issues and themes identified above. The emerging conflicts between traditional values held within the information profession and the emerging values held by governments were of particular interest.

A small scale exploratory study of professional opinions on the above issues was initiated with the intention of identifying, by way of open ended questions posted to a variety of professional listservs, the current issues confronting librarians within the field of social responsibility. 


\section{The literature}

The bookstores are currently overwhelmed by titles that include the words 'social responsibility' and books about libraries have not escaped the trend to deal with the topic. Indeed there has been a spate of recent interest in libraries and social responsibility adding to earlier North American writers such as MacLeish and Schuman. (Campbell,. 2005; Durrance and Fisher, 2005; Kranich, 2001; MacLeish, 1971; McCabe, 2001; Molz \& Dain, 1999; Rosenzweig, 2004; Schuman, 1976; Smith, 2001).

McCabe writes about civic librarianship and frames his discussion with the idea of community building. He surveys the history of libraries in America and also looks at some of the philosophy that has defined different eras, eventually looking at the 1980s and libertarianism. He notes that libertarians are politically left or right and but find agreement in freedoms enjoyed by individuals and restricted government control. (McCabe, 2001, 15). From the libertarianism of the 1980's, McCabe moves into a discussion of the Community Movement and its response to the libertarianism of the previous decade. It is agreed that individual liberty is important but also recognizes as equally important, "social morality and civic duty." (McCabe, 2001, 22)

McCabe further argues that the history of libraries is shaped by these political movements; noting that today's public libraries are a combination of libertarian and traditional values. Libraries were once very moralistic places and arguably many may still be and feel as very superior in a cultural sense. Libraries were also once very systemcentered, stereotypically rule-bound and designed according to those who ran them. A clear paradigm shift has occurred in recent years from a system orientation, where the collection was of central concern, to user-focused philosophy where the client is the focus, has defined perceptions of what constitutes good library service..

Indeed one obvious change for society and libraries is technological change. Much has been written on that topic. (Barnett, 2002; Milam, 2001) Gorman, (2003) who has perhaps been the most influential writer in North America, has written a book examining the development of innovations and the repercussions for the libraries of the future. Gorman looks at enduring issues such as literacy and presents a research agenda for public libraries.

In an article that discusses the development and current state of technological services of urban public libraries, Milam states "the library has always been the place where worlds reside--on paper. Today, it creates and organizes worldwide, Web-based information that promotes connection to local resources for civic information and engagement." (Milam, 2001, 216)

Berry makes the observation, supported by this study that more emphasis on the topic of public policy to support and provide context to library technology is required in library and information studies. (Berry, 2000,6) It is arguable that we have 'overdone' technology, concerned ourselves too greatly with access to an information overload machine (the Internet) at the expense of putting communication and community first. 
Berry's sentiments echoed tensions outlined by other pre 9/11 writers (Molz \& Dain, 1999) who pointed to the contradiction of the library as a social space and the ever increasing demands and possibilities afforded by technologies to go beyond fixed spaces.

Electronic technology and changing ways of life are eroding boundaries of space and time and transcending governmental jurisdictions, but the persistence of such jurisdictions, together with economic constraints, imposes limits on fulfilling visions of universal service. Still, the traditional public library-popular, nonpartisan, community based, and within real, not virtual, walls-carries important social value. It contributes to what social scientist Robert Putnam calls the "network of civic engagement" that anchors people to communities and fosters a sense of fellowship, civic participation, and democratic living. As a civic space, devoted to cultural and educational purposes, the public library serves to reinforce social solidarity in an increasingly fragmented and market-driven culture. Some of the same social needs it was created to meet still exist but in different forms and in a very different environment: public libraries have both changed and remained the same. They arose as mediating institutions in a time of social transformation, then adapted to the needs of a modernizing world, and now, in a postmodern, postindustrial world, are navigating through changes whose impact we are only beginning to assess. (2-3)

The people

The listservs Publib (http://lists.webjunction.org/publib) and Pubyac (www.pubyac.org) were used as a means of assessing current attitudes towards issues of social responsibility. (Listservs are mailing lists to which one can subscribe to exchange information and engage in discussion with other like-minded individuals who are also subscribed. Listservs are usually created to support professional or recreational interests.) Both Publib and Pubyac are of interest to public libraries and public librarians, the latter being of specific interest to those in youth services. Although primarily North American, they encourage international subscribers.

Two questions were explored over a period of weeks. These were:

a) What do you believe are the social aspects of the role of the public library. (Whatever you feel that is... and feel free to discuss this in your reply.)

b) Has that role changed in a 'post-9/11' world and if yes, how? If not, why not?

All respondents to the questions acknowledged a continuing strong role for public libraries in society. The most common theme in the responses noted that social responsibility included the provision of opportunities for learning across entire communities, regardless of age and social position. The second most common response 
affirmed that the public library had a community role, providing a place for the community to belong and to find and use resources free of charge.

One respondent noted literacy and a hint of information literacy as an enduring role: [The library's role] is to promote and enable an informed, literate society.

Another cited the digital divide as being a continuing focus for public libraries: In actuality, there is still a significant portion of society which a) has no computer access outside the library, and/or b) is not comfortable using the computer as a communication tool. The library has the responsibility to help these people bridge the information gap in ways that work for them.

Storytime was identified as a key social outreach. The predominance of youth service librarians as contributors to the listservs explains the bias towards youth services. This not withstanding, storytime is a cornerstone of public library service to the community. It would likely be the most visible and popular of public library programs and is historically and currently an important outreach service. But furthermore, it provides a reason for adults to take their children to a public library and while the child is being read a story the adults can engage with their own services.

Respondents generally noted that the post-9/11 context had not, in any permanent or sustained way, changed the role of libraries and the importance of social responsibility. One respondent noted that immediately following the events of 9/11 there was a greater feeling of community, generally, and this was particularly felt by public libraries, that situation has lessened.

Another respondent focused on public policy, noting that there has been a change in the role of public libraries, notably in privacy protection:

It seems that librarians have become (we hope) one of the guardians of civil liberties, by doing battle with parts of the Patriot Act and by protection the privacy of customers.

And another respondent echoed these concerns:

Before the Patriot Act it was easy to say that people should have free access to materials and information without really having to define or defend that position. The Patriot Act has really forced us to think about what we are willing to do to protect the intellectual freedom of our communities. I tend to be idealistic, but I see the library as a protector - we had intellectual freedom before it was an issue, we maintain that freedom while many are calling for its limitation, and hopefully that freedom will be a constant throughout the pendulum swing between stringent and loose policies.

Another respondent linked the events of 9/11 to general changes in society leading to greater disparity. More unemployment, a rise in literacy and diversity issues due to immigration and the social issues that follow these circumstances affect a significant number of North American communities. 
The findings of this small informal survey yielded rich anecdotal evidence of an enduring and important role for public libraries in a world that accelerates in social complexity and challenge. Anonymous librarians were compelled to share their thoughts despite hectic work schedules to share their perceptions of professional ethics and library roles.

The study was intended to be small-scale, and indeed limited by the small number of respondents who engaged through listserv posting. It could also be argued that those belonging to and regularly checking and responding to listserv inquiries are already engaged in professional debate, leaving out a portion of the potential study group.

Also noted is the North American bias in the sample. It was felt by the authors that this was mitigated by the international subscription list of these listservs. As well, the concept of social responsibility and recent changes to this social responsibility was better addressed by countries where communities were engaged in debate because of government responses to $9 / 11$.

Nevertheless the study has demonstrated that social responsibility is an issue for librarians serving the public and further investigation is warranted to determine how the post 9/11 debate is being played out by information professionals.

\section{Conclusion}

A review of the literature together with informed responses of respondents to public library listservs provides evidence that public librarians perceive that the social aspects of library service are important and that the push towards a digital world needs a counter point that can be offered by the social space afforded by libraries. The social roles taken on by public librarians, learning, literacy and equal access, are likely to find resonance with school librarians. Has the post 9/11 world had an effect on school libraries in the same way that it has affected public libraries? Who else in the school community is defending the social conscience? In a world that is becoming more polarized yet increasingly multicultural the libraries that serve the public are a bulwark against extremism and the rule of fear and ignorance.

\section{References}

ALA. (2005). Statements and policies. Retrieved March 15, 2006 from http://www.ala.org/ala/oif/statementspols/statementspolicies.htm\#access

ASLA. (1994). Policy Statement - Electronic Information Literacy. Retrieved March 15, 2006 from http://www.asla.org.au/policy/p_eilit.htm

ASLA. (2000). ASLA Policy Statement - School Library Bill of Rights. Retrieved March 15, 2006 from http://www.asla.org.au/policy/p_bor.htm 
Barnett, Andy (2002). Libraries, community, and technology. Jefferson, N.C.: McFarland.

ATLC. (1995). Students bill of rights. Retrieved March 15, 2006 from http://www.caslibraries.ca/files/StudentsBillEnglish.pdf

Berry, John N. (2000). Educating for library jobs: Need graduate programs focused on librarianship. Library Journal, 125(17), 6.

Brown, B (2003). On the road again: delivering information literacy to regional Queensland . In Proceedings ITiRA Conference 2003, Caloundra, Queensland

Campbell, B. Feliciter. (2005), "In" versus "With" the Community: Using a Community Approach to Public Library Services. Feliciter, 51(6).

CILIP. (2005). CILIP Statement on Intellectual Freedom, Access to Information and Censorship. Retrieved, March 15, 2006 from http://www.cilip.org.uk/professionalguidance/foi/intellfreedom.htm.

Durrance, J. and Fisher, K.. (2005). How libraries and librarians help : a guide to identifying user-centered outcomes. Chicago: American Library Association.

Gorman, M. (2003).The enduring library: technology, tradition, and the quest for balance. Chicago: American Library Association.

Beacons of the Information Society: The Alexandria Proclamation on Information Literacy and Lifelong Learning. (2005). Retrieved March 15, 2006 from http://www.ifla.org/III/wsis/BeaconInfSoc.html

Libraries \& democracy : the cornerstones of liberty. (2001). Kranich, N. (Ed.) Chicago: American Library Association, 2001.

MacLeish, A. (1971). Champion of a cause: Essays and addresses on librarianship. Chicago: American Library Association.

McCarthyism. (n.d.) Retrieved March 15, 2006 from http://www.spartacus.schoolnet.co.uk/USAmccarthyism.htm

Milam, Danielle Patrick Access for all: Public library contributions to civic connectivity. National Civic Review, (90), 3, 213-21.

Molz, R. K., and Dain, P. (199). Civic Space/cyberspace: The American Public Library in the Information Age. Cambridge, Mass: MIT Press

Rosenzweig, M. (2005). The basis of a humanist librarianship in the ideal of human autonomy. Progressive Librarian, (23), 40-5. 
Schuman, P. (1976). Social responsibilities and libraries: A Library journal/School library journal selection. New York: R. R. Bowker.

Skov, A. (2004). Information literacy and the role of public libraries. Scandinavian Public Library Quarterly, (37), 3 http://www.splq.info/issues/vol37_3/02.htm

Smith, M. (2001). Managing the internet controversy. New York: Neal-Schuman.

\section{Biographical notes}

James Henri is Associate Professor in the Division of Information \& Technology Studies, Faculty of Education and Adjunct Associate Professor, School of Professional and Continuing Education, University of Hong Kong. He is also active in advancing the profession as Chair, IFLA Section for School Libraries and Resource Centers and Vice President, IASL. Sandra Lee, a former colleague at the University of Hong Kong taught in the programs in which James continues to teach: the MSc Library and Information Management program and the BEd Library and Information Studies program. A BSc in Information Management has been added to the programs at HKU. James arrived at HKU in 2001 from Australia where he taught at Charles Sturt University. Sandra is originally from Canada and worked as a youth services librarian and information specialist. 
Reproduced with permission of the copyright owner. Further reproduction prohibited without permission. 